Brit. F. industr. Med., 1966, 23, I81.

\title{
Relevance of Respiratory Symptoms and Signs to Ventilatory Capacity Changes after Exposure to Grain Dust and Phosphate Rock Dust
}

\author{
BRYAN GANDEVIA* and BLAIR RITCHIE \\ From the Departments of Medicine, University of Melbourne and University of New South Wales
}

\begin{abstract}
Ventilatory capacity was measured before and after exposure to high concentrations of wheat dust in 24 men, 18 of whom were similarly studied while working with calcium phosphate rock. Changes in ventilatory capacity were examined in relation to respiratory symptoms as commonly elicited in occupational surveys, and to the presence or absence of a productive cough on request and under observation. A significant decrease in the forced expiratory volume at one second was observed within half an hour of beginning work in the wheat dust, and this decrease was maintained throughout the work shift. A smaller significant decrease was found on exposure to phosphate rock over several hours, no significant change occurring within the first half-hour. Greater or more consistent decreases were recorded in those men who gave a history of persistent cough and sputum, and more particularly in those who had a productive cough on request, than in those without these features. A history of symptoms on exposure failed to define a group showing any more severe ventilatory reaction on exposure to wheat dust than the average. Some of the factors influencing the history of symptoms in occupational populations are reviewed, and the advantage of an objective sign, as provided by a deliberate cough, is indicated in defining an 'abnormal' group within such a population.
\end{abstract}

This study of the acute effects on ventilatory capacity of grain and phosphate rock dusts in high concentration was undertaken in 196I prior to an investigation of the long-term effects of grain dust on the lungs of workers handling it frequently. In the event, no long-term effects of wheat dust were demonstrated in a survey of an entire working population (Gandevia and Ritchie, to be published), but the short-term investigation of a small group is of interest in relation to recent work on the changes in ventilatory capacity during the day in workers in a variety of occupations involving exposure to vegetable dusts. It also provides further evidence in support of a view previously expressed (Gandevia and Milne, I965a) that the objective sign of an observed productive cough defines better two subgroups of an industrial population than does a history of cough and sputum, whether these symptoms are constant or occur merely on exposure to the relevant dust.

*Address for reprint requests: Prince Henry Hospital, Little Bay, New South Wales, Australia.

Received for publication I6 August, 1965.

\section{Background Information}

In the bulk loading of wheat, a conveyor belt carries the grain from the silos to the ship's hatch where it is poured down a chute into a 'trimming' machine delivering a stream of wheat at a rate of up to 75 tons per hour; two are commonly used in one hold. An operator controls the direction of the stream by pressing buttons on a portable control panel (hence the term 'button-men') and thus ensures even distribution of the grain. This work may be carried out in a poorly ventilated, confined space, particularly as the level of the grain approaches the level of the deck, and visibility may be reduced to a few feet by the dust. Normally the button-men wear loose-fitting air-line respirators, and they work for half-hour periods with similar rest breaks for a normal working shift of eight hours. Dust counts with the only instrument available to us (Owens) were unsatisfactory owing to the extremely high concentrations and the very wide range of particle size. For our purposes at the time, it was sufficient to ensure that the dust concentrations were in excess of those normally encountered. This $8 \mathrm{I}$ 
was done by requiring the men to work without respirators for their first half-hour 'spell' in the dust; for the remainder of the shift their working conditions were as usual.

Phosphate rock, imported mainly from Nauru and Ocean Island, is up to $96 \%$ (commonly about $85 \%$ ) pure tri-calcium phosphate, compressed in nature to almost rock-like consistency and dried before shipment. Unloading is carried out mainly by mechanical means, but the fragmented rock in less accessible parts of the hold is shovelled by hand to where it can be picked up by a 'grab'. For the first half-hour of exposure to this dust, worse than average working conditions (a sufficient definition for our purposes) were maintained by periodically releasing a load of rock into the hold from deck level, thus adding significantly to the dust created during routine operations. For the remainder of the shift, the men worked in the normal way. Respirators were not supplied.

\section{Dust Composition}

The composition of wheat dust is complex for, in addition to fragments of husks, grain, and the plant itself, there are soil particles, grass and weed pollens, mould spores, other organic material, and also siliceous opal phytoliths (Baker, 196I). Crude extracts of the dust do not cause a wheal reaction in normal human skin, although they may do so in susceptible subjects showing no skin sensitivity to grass pollen or fungal or house dust extracts (Gandevia, in preparation). Fumigation with phosphine is carried out in the silos or collection areas, but no gas remains by the time the grain is loaded (A. Christophers, personal communication).

The phosphate of lime is almost insoluble, relatively inert, and subjectively much less irritating to inhale than wheat dust. By contrast with wheat dust, it is not considered to be a significant source of acute or chronic respiratory symptoms; it was studied because it is probably the least 'annoying' of dusts encountered on the waterfront.

\section{Plan of Investigation}

The essential plan for the study was simple although several practical problems were encountered. The men were interviewed and examined, and estimations of ventilatory capacity were performed before and after their first (half-hour) exposure to dust at the beginning of a shift. On the wheat ship three successive eight-hour shifts of button-men were studied (day, evening, and following day) but only the first two shifts, each comprising seven men, were followed to the end of the eight hours of the shift. As no effect of shift was demonstrable, the data for the 24 subjects concerned have been pooled.
Several weeks later, a random selection of 18 of the same men was rostered to unload phosphate rock. Interview and examination were not repeated, but ventilatory tests were done before and after the first half-hour of exposure and again at the end of the shift. Various interruptions, including a transient 'walk-off', delayed the first (halfhour) exposure to phosphate rock dust until about midday, so that the observations for the whole of this shift in fact relate to little more than half a normal working day. As pointed out above, the exposures to both dusts in the first half-hour were deliberately planned to involve dust concentrations in excess of those encountered in normal working conditions.

Questionnaire on Respiratory Symptoms Before exposure to wheat dust, the British Medical Research Council questionnaire on respiratory symptoms (1960), slightly modified, was completed by one of us (B.G.) for all the subjects. Additional questions related to the duration of employment, frequency with which dusty cargoes were worked, and family history of allergic diseases. Finally, as casually as possible, the men were asked 'Does the wheat dust worry you at all ?' and, if it did, 'In what way ?' All the symptoms mentioned-and these were sufficiently varied to include diarrhoea and constipation-were noted with equal interest. If respiratory symptoms were mentioned, a detailed enquiry was made. The men were finally asked specifically whether the dust caused skin, eye, or nasal irritation, cough, sputum, wheeze, or shortness of breath (climbing out of the hold after exposure provided a test). If any of these symptoms had previously been volunteered they were not mentioned again. 'Symptoms on exposure' in this paper implies the development of cough with sputum and/or wheezing and/or shortness of breath; a trivial dry cough on exposure has not been considered significant, and the remaining 'non-pulmonary' symptoms, which were sought partly to minimize emphasis on the respiratory system, have been ignored. A history of symptoms on exposure to phosphate rock was not specifically sought, but when the men were asked at the end of the interview whether wheat or phosphate dust was the more objectionable there was a uniform preference for working with the latter.

A history of persistent cough and sputum in this series implies that these symptoms had been present persistently for an indefinite period exceeding three years, and present at any time of day for most days of the week, winter and summer. No subject had had a chest illness in the previous three years, within which period all had had a normal mass survey chest radiograph taken. All claimed a normal exercise tolerance. They had all previously worked grain and phosphate rock cargoes, commonly for three or four days at a time several times a year. None of the men worked with wheat on the day before the investigation of this dust; about a third had worked the phosphate rock cargo on the preceding day.

The average age of the entire series was $40.9 \pm$ II.O years. Twenty-one of the 24 men in the wheat group and 17 of the 18 subjects in the phosphate rock group were cigarette smokers, and the effect of smoking cannot therefore be examined. 
Physical Examination Before the wheat dust study, clinical examination of the chest was carried out by one of us (B.R.) in ignorance of the history given to the other. Both before and after exposure each subject was observed while he took a deep breath and coughed in an effort to produce a specimen of sputum in a container. A 'productive cough' was considered to be present if a specimen was produced or if the cough was adjudged 'loose' by ear whether or not there was expectoration into the container. The term 'productive cough' in this paper relates to this sign and not to a history of cough and sputum. No evidence of localized pulmonary disease or of significant cardiovascular disease was found. The histories and clinical examinations were not repeated during the phosphate rock study.

Ventilatory Studies Before the wheat dust study most of the subjects were given some practice in performing ventilatory tests with the Wright peak flow meter.

Measurements of ventilatory capacity before and after the first exposure, and at the end of the shift, were performed in the nearest available cabin; men had to climb out of the hold and up a further stairway for the measurements after exposure. Spirograms, from which the forced expiratory volume at one second (F.E.V.1.0) was later derived, were recorded in the conventional manner, with the subject seated, using a low resistance spirometer and Palmer kymograph. Separate measurements of vital capacity (V.C.) (from an unhurried expiration) were also made during the wheat dust study. The highest of three satisfactory estimates was accepted, 'satisfactory' being defined, in the case of the forced expiratory spirograms, as almost identical, as judged by eye, and free from evidence of artefacts or lack of co-operation. For the vital capacity, the highest of three attempts showing close agreement (within about $300 \mathrm{ml}$, as judged by the vertical record of bell movement) was accepted. The ratio of F.E.V.1.0 to V.C. was subsequently calculated. All gas volumes are expressed in litres, B.T.P.S.

\section{Results}

Findings in the Series as a Whole The mean F.E.V.1.0 for the entire series (24 subjects) before exposure to wheat dust was $3.31 \pm 0.80$ litres $(95.5 \%$ of mean normal values as predicted from

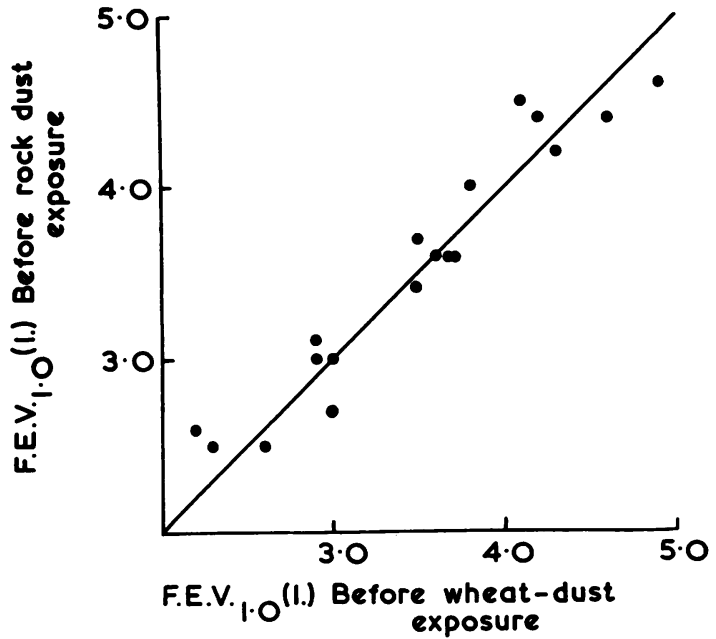

FIGURE. F.E.V $\cdot_{1 \cdot 0}$ before exposure to wheat dust and before exposure to phosphate rock dust for men exposed to both dusts. There is no significant difference in ventilatory capacity at the beginning of the exposures.

age and height), and the mean F.E.V.1.0 ${ }_{\cdot \text { V.C. ratio }}$ was 0.804 . For the 18 men from this group subsequently exposed to phosphate rock dust the mean F.E.V.1.0 was $3.53 \pm 0.72$ litres and the mean of the ratio was 0.790 . For the men concerned the average difference $(34 \mathrm{ml}$.) between the initial values before exposure to each of the two dusts does not differ significantly from zero, and graphically the points are seen to lie along the line of identity (Figure).

The mean change in F.E.V.1.0 in the wheat dust was - I4I ml. over a single exposure (half an hour) and $-291 \mathrm{ml}$. over the whole shift, both decreases being significant (Table I.I, I.2). The comparable figures in phosphate rock were $-43 \mathrm{ml}$. and - I07 $\mathrm{ml}$., only the latter being a significant change (Table I.3, I.4). Excluding from the wheat dust series the six men who were not exposed to phosphate rock, the mean decrease in F.E.V.1.0 over a single exposure to wheat dust was still $-130 \mathrm{ml}$.

TABLE I

Mean Change in F.E.V.1.0 (Litres) on Exposure

$\begin{array}{lllll}\bar{x} & n & s & t & P\end{array}$

I. Wheat dust

First exposure

2. Wheat dust

Whole day

3. Phosphate rock dust First exposure

4. Phosphate rock dust Whole day

$\begin{array}{lllll}-0.141 & 24 & 0.291 & 2.37 & <0.05>0.025 \\ -0.291 & 14 & 0.266 & 4.09 & <0.005>0.001 \\ -0.043 & 18 & 0.233 & - & \text { n.s. } \\ -0.107 & 18 & 0.160 & 2.84 & <0.02>0.01\end{array}$


and was of the same order of consistency. In comparing the reactions of the two series it is therefore convenient and justifiable to use the full number of observations.

It is concluded that, under the conditions of these exposures, wheat dust had more effect in producing a decrease in ventilatory capacity, and this change is manifest within half an hour.

Subsequent analysis is concerned with the change in F.E.V.1.0 in relation to symptoms on exposure, history of persistent cough and sputum, and productive or unproductive cough. Changes in vital capacity are summarized.

Symptoms on Exposure Twelve men complained of developing respiratory symptoms on exposure to wheat dust, as defined above. For this group the mean change in F.E.V.1.0 for one halfhour exposure was $-58 \mathrm{ml}$, and for the whole shift $-330 \mathrm{ml}$., only the latter decrease being significant. For those without symptoms the comparable figures were $-207 \mathrm{ml}$. and $-269 \mathrm{ml}$., both of which are significant (Table II). The difference in reaction between the two groups with and without symptoms is not significant $(P>0.05)$ for either period of exposure.

It is concluded that in this series the presence or absence of a history of developing symptoms on exposure to wheat dust does not influence ventilatory capacity changes over a shift, although the decreases are more pronounced within half an hour in the asymptomatic subjects. This finding is anomalous, especially if, as suggested for cotton exposure (McKerrow, McDermott, Gilson, and Schilling, I958), the rate of change of ventilatory capacity is related to the development of symptoms.

History of Cough and Sputum A history of persistent cough and sputum was given by $13 \mathrm{men}$, Io of whom were studied in both dusts. On exposure to wheat dust, those with a history of cough and sputum showed a decrease in F.E.V.V.1.0 of
$195 \mathrm{ml}$. (which borders on statistical significance) over half an hour, and of $465 \mathrm{ml}$. (P $>0.00 \mathrm{I}$ ) over the whole shift (Table III.I, III.2). The respective decreases for the subjects without a history of cough and sputum are $77 \mathrm{ml}$. and $160 \mathrm{ml}$., neither fall being significant (Table III.3, III.4). The difference in behaviour of the two subgroups is significant over the whole day but not over half an hour (Table III.5).

As might be expected from the lesser overall change in phosphate rock dust, the decreases in F.E.V.1.0 in those with and those without a history of cough and sputum are less impressive and are not significant for a half-hour exposure (Table III.6, III.8). The decrease over the whole shift is comparable in these subgroups (about $100 \mathrm{ml}$.) (Table III.7, III.9) but is significant only for those with a history of cough and sputum.

It is concluded that the reaction of the bronchi to both dusts is significantly related to a history of persistent cough and sputum and that the effect is progressively more marked over the day.

Productive Cough Thirteen men were observed to have a productive cough on request, eight before, or before and after, exposure, and five only after their first half-hour of exposure. As the reactions of these two groups appear to be identical (for example, mean decreases in F.E.V.1.0 of $-285 \mathrm{ml}$. and $-282 \mathrm{ml}$. over a half-hour exposure), the analysis below regards them as one group; it is not known whether the discrepancy on two examinations is due to the error of the test or to the genuine development of sputum during exposure.

The redistribution of the series in terms of a productive cough instead of a history of productive cough is pertinent. Of the 13 men who admitted to cough and sputum, a productive cough was observed in nine. Of the II subjects who denied cough and sputum, a productive cough was observed in four.

On exposure to wheat dust, those with a produc-

TABLE II

Mean Change in F.E.V.1.0 (Litres) In Relation to Symptoms on Exposure

$\begin{array}{lllll}\bar{x} & n & s & t & P\end{array}$

\begin{tabular}{|c|c|c|c|c|c|}
\hline \multicolumn{6}{|l|}{$\begin{array}{l}\text { Symptoms present } \\
\text { Wheat dust }\end{array}$} \\
\hline Whole day & -0.330 & 5 & 0.222 & $3 \cdot 33$ & $<0.05>0.025$ \\
\hline $\begin{array}{l}\text { Symptoms absent } \\
\text { Wheat dust }\end{array}$ & 0.307 & ? & 0.?०⿱ & 0.28 & 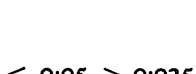 \\
\hline Whole day & -0.269 & 9 & 0.301 & $2 \cdot 68$ & $<0.05>0.025$ \\
\hline
\end{tabular}


TABLE III

Mean Change in F.E.V.1.0 (Litres) on Exposure in Relation to History of Cough and Sputum

\begin{tabular}{|c|c|c|c|c|c|}
\hline & $\bar{x}$ & $n$ & $s$ & $t$ & $P$ \\
\hline $\begin{array}{l}\text { Wheat dust } \\
\text { Positive history }\end{array}$ & & & & & \\
\hline $\begin{array}{l}\text { I. First exposure } \\
\text { 2. Whole day }\end{array}$ & $\begin{array}{l}-0.195 \\
-0.465\end{array}$ & $\begin{array}{r}13 \\
6\end{array}$ & $\begin{array}{l}0.224 \\
0.158\end{array}$ & $\begin{array}{l}2 \cdot 17 \\
7 \cdot 21\end{array}$ & $\begin{array}{l}<0.10>0.05 \\
<0.001\end{array}$ \\
\hline $\begin{array}{ll}\text { Negative history } \\
\text { 3. } & \text { First exposure } \\
\text { 4. } & \text { Whole day } \\
\text { 5. } & \text { Comparison of } 2 \text { and } 4\end{array}$ & $\begin{array}{r}-0.077 \\
-0.160 \\
0.305\end{array}$ & $\begin{array}{r}11 \\
8 \\
14\end{array}$ & $\begin{array}{l}0.246 \\
0.296 \\
0.226\end{array}$ & $\begin{array}{l}- \\
1 \cdot 53 \\
2 \cdot 48\end{array}$ & $\begin{array}{l}\text { n.s. } \\
<0.20>0.10 \\
<0.05>0.025\end{array}$ \\
\hline $\begin{array}{l}\text { Phosphate rock dust } \\
\text { Positive history } \\
\text { 6. First exposure } \\
\text { 7. Whole day }\end{array}$ & $\begin{array}{l}+0.012 \\
-0.103\end{array}$ & $\begin{array}{l}\text { 10 } \\
\text { I0 }\end{array}$ & $\begin{array}{l}0 \cdot 188 \\
0.102\end{array}$ & $\frac{-}{3 \cdot 19}$ & $\begin{array}{l}\text { n.s. } \\
<0.02>0.01\end{array}$ \\
\hline $\begin{array}{l}\text { Negative history } \\
\text { 8. First exposure } \\
\text { 9. Whole day }\end{array}$ & $\begin{array}{l}-0.113 \\
-0.111\end{array}$ & $\begin{array}{l}8 \\
8\end{array}$ & $\begin{array}{l}0.300 \\
0.220\end{array}$ & $\begin{array}{l}1 \cdot 07 \\
1 \cdot 43\end{array}$ & $\begin{array}{l}<0.40>0.30 \\
<0.20>0.10\end{array}$ \\
\hline
\end{tabular}

TABLE IV

Mean Change in F.E.V.1.0 (Litres) on Exposure in Relation to Productive Cough under Observation

$\begin{array}{llllll}\bar{x} & n & s & t & P\end{array}$

Wheat dust

Present

I. First exposure

2. Whole day

$-0.278$

$-0.424$

13
8

$+0.021$

$-0.113$

0.299

0.311

$+0.050$

$-0.064$

9

8. Whole day

$-0.137$

$-0.149$

9. First exposure

ro. Whole day

I4

Phosphate rock dust

Present

Absent

$\begin{array}{lll}\text { 3. First exposure } & +0.021 \\ \text { 4. Whole day } & -0.113 \\ \text { 5. Comparison of } 1 \text { and } 3 & 0.299 \\ \text { 6. Comparison of } 2 \text { and } 4 & 0.311\end{array}$

n

\section{$P$}

$\begin{array}{lll}0.266 & 3.77 & <0.005>0.001 \\ 0.156 & 7.69 & <0.001\end{array}$

- n.s.

$\begin{array}{lll}0.239 & - & \text { n.s. } \\ 0.293 & - & \text { n.s. } \\ 0.254 & 2.87 & <0.01>0.005 \\ 0.224 & 2.55 & <0.05>0.025\end{array}$

$2 \cdot 87$
$2 \cdot 55$

$<0.05>0.025$

II

24

0.224

0.120

I. 25

$<0.30>0.20$

0.076

$2 \cdot 53$

$<0.05>0.025$

0.286

$1 \cdot 44$

$2 \cdot 12$

$<0.20>0.10$

$<0.10>0.05$

tive cough showed highly significant mean decreases in F.E.V.1.0 of $278 \mathrm{ml}$. over half an hour and of $424 \mathrm{ml}$. over the whole shift (Table IV.I, IV.2). The respective figures for those without a productive cough were $+21 \mathrm{ml}$. and $-113 \mathrm{ml}$., neither of which is statistically significant (Table IV.3, IV.4). Reactions over both periods were significantly greater in those with a productive cough (Table IV.5, IV.6).

The trends are similar but less striking on exposure to phosphate rock dust. The changes are not significant over one exposure (Table IV.7, IV.9). Over the day only the decrease for the subjects with productive cough is significant, although

it is smaller on the average than for those whose cough was unproductive (Table IV.8, IV.IO).

It is concluded that a productive cough under observation and on request differentiates a group of subjects suffering greater or more consistent decreases in ventilatory capacity on exposure to wheat or phosphate rock dust. This finding has also been observed in workers exposed to jute and, less clearly, to cotton (Gandevia and Milne, 1965a and b) and isocyanate vapour (Gandevia, 1964).

Changes in Vital Capacity The changes in vital capacity were analysed only in relation to wheat dust exposure. They closely follow the changes in 
F.E.V.1.0 but are in general of a slightly lower order both of magnitude and statistical significance. It follows that on the average a small decrease in the ratio F.E.V $\cdot \cdot_{1 \cdot 0}$ :V.C. is associated with exposure to dust. As the vital capacity estimations in this study were separate from the F.E.V.1.0 estimations, they may be regarded as offering independent confirmation of the F.E.V.1.0 findings, to which they otherwise add nothing.

The numbers are too small to permit valid interpretation of an analysis of the changes in F.E.V. $\cdot_{1 \cdot 0}$ in relation to the ratio F.E.V.1.0 :V.C. However, in view of conflicting observations on this point in cotton and jute workers (Gandevia and Milne, 1965a and $b$ ), it should be mentioned that those with the higher ratios $(>0.80)$ showed the more consistent decreases in F.E.V.1.0 on exposure to both dusts, perhaps more particularly to the wheat dust.

\section{Discussion}

This study relates to a selected population, in that the subjects were not medically exempted from dusty work (as many men were), and to environmental dust concentrations well in excess of those normally encountered. Especially since a nonspecific effect of high dust concentrations is not excluded, the findings are not necessarily directly relevant to the acute respiratory syndrome which may occur on occupational exposure at least to wheat dust.

The data are primarily of interest in relating respiratory symptoms and signs to the observed changes in ventilatory capacity. Although it is shown that a history of cough and sputum is associated with somewhat greater or more consistent decreases in ventilatory capacity than occur in those without this feature, a productive cough under observation and on request provides a better basis for distinguishing the subjects showing the greater falls in F.E.V.V.1.0 or V.C. In so far as this is an objective sign, it has an obvious advantage over the history in defining a group with respiratory 'abnormality'. A history of cough and sputum is subjective; we believe that some subjects, perhaps those more introverted or married to the more fastidious wives, will record it as present more readily than others. In occupational surveys, the reliability or accuracy of the history is also influenced by concern that any existing hazard should be detected, a factor affecting the group as a whole and doubtless of varying significance from one occupational group to another, and by concern on the part of individuals that medical reclassification may mean loss of pay or even of job. We have good reason to believe that both factors were operative in the present series. We do not suggest that a significant proportion of the working population is deliberately untruthful; it is merely postulated that any population, particularly an occupational one, may be subject to bias, a characteristic which epidemiologists are accustomed to accepting in observers.

The 'observed cough' technique has a number of advantages for epidemiological work: it is objective, simple, and quick to use, it can be employed in spite of a language barrier, and it has not been rejected by any of over a thousand subjects asked to do it. Collection of morning sputum specimens, successfully used by Fletcher, Elmes, Fairbairn, and Wood (1959), appears to be unacceptable to Australians, in whom the lapse rate has been of the order of 30 to $40 \%$ (Bell, 1963; personal observations). Disagreement between observers in recording a deliberate cough as productive or not occurs in about $10 \%$ of cases (unpublished data).

The objections to the history of chronic cough and sputum apply with greater force to a history of symptoms on exposure. In the present series there is little evidence of a significant difference in ventilatory response on exposure to wheat dust between those with and those without these symptoms. By contrast, studies of subjects exempted from work with wheat dust on medical grounds show that a history of symptoms on exposure is frequently associated with positive skin tests, and sometimes with considerable decreases in ventilatory capacity, occasionally amounting to frank asthma, in response to an aerosol extract of wheat dust (Gandevia, in preparation).

The expert administrative and technical assistance of Miss Nancy Rogers made this work possible. Mrs. Heather Lovell carried out the statistical analysis and prepared the figures. We are grateful for the technical help of Drs. T. Mathew, J. Long, B. Cutter, J. Frayne, and W. Carter, then medical students, and of Mr. W. J. Shaw, formerly senior factory inspector in the Division of Industrial Hygiene, Victorian Health Department. The whole-hearted co-operation of employers, employees, and their union representatives, port and stevedoring authorities and ship's personnel, all of whom had their routine upset, is gratefully acknowledged. Our thanks are particularly due to the Association of Employers of Waterside Labour, the British Phosphate Commissioners, and the Grain Elevators Board, for their support and interest. We have had valuable help and advice on various aspects from Dr. B. Jarvis, Dr. D. L. G. Thomas, Dr. A. Christophers, and Professor R. R. H. Lovell. Dr. Jarvis has also kindly read and amended our draft. At the time of this study one of us (B.G.) held the Ernest F. Atkins Senior Fellowship in Industrial Medicine in the University of Melbourne. 


\section{REFERENCES}

Baker, G. (196r). Opal Phytoliths and Adventitious Mineral Particles in Wheat Dust. Mineragraphic Investigations Technical Paper No. 4, C.S.I.R.O., Melbourne.

Bell, A. (1963). Air Pollution from Metallurgical Industry. The Effects on Health of the Residents of East Port Kembla. Summary report of Division of Occupational Health, New South Wales.
Fletcher, C. M., Elmes, P. C., Fairbairn, A. S., and Wood, C. H. (1959). Brit. med. F., 2, 257.

Gandevia, B. (1964). Aust. Ann. Med., 13, 157. and Milne, J. (1965a). Brit. F. industr. Med., 22, 187. , - (I965b). Ibid., 22, 295.

Mckerrow, C. B., McDermott, M., Gilson, J. C., and Schilling, R. S. F. (1958). Ibid., 15, 75 .

Medical Research Council's Committee on the Aetiology of Chronic Bronchitis (1960). Brit. med. F. 2, 1665. [See Brit. F. industr. Med. (1965), 22, 203]. 